\title{
Study on the reverse osmosis in concentrating phosphorus from simulated biogas slurry
}

\author{
Xiaofeng $\mathrm{BAI}^{\mathrm{a}}$, Zifu $\mathrm{LI}^{\mathrm{b}}$, Xuemei WANG ${ }^{\mathrm{c}}$, Shikun $\mathrm{CHENG}^{\mathrm{d}}$, Xue BAI ${ }^{\mathrm{e}}$ \\ Civil \& Environmental Engineering School, University of Science \& Technology Beijing, Beijing \\ 100083, China \\ a huanjing060546@163.com, b zifulee@yahoo.com.cn, c wangxuemei0000@126.com, \\ ${ }^{d}$ chengshikun_1985@yahoo.com.cn, ${ }^{\text {e}} 523602728 @ q q . c o m$
}

Keywords: biogas project; biogas slurry; reverse osmosis; Phosphorus recovery

\begin{abstract}
Biogas slurry as an inevitable outcome of biogas project contains a lot of nutrients such as nitrogen and phosphorus. In order to solve the difficulties in storage of biogas slurry and recycle the nutrients, phosphorus from simulated biogas slurry was concentrated by reverse osmosis membrane. Economic evaluation of the system is also analyzed in the paper. Results showed that the reverse osmosis membrane has good concentration effects on phosphorus from biogas slurry. Finally, phosphorus content in concentrated effluent increased 7.8 times, 8 times, 10.4 times from simulated biogas slurry of different initial concentrations $(60 \mathrm{mg} / \mathrm{L}, 90 \mathrm{mg} / \mathrm{L}, 120 \mathrm{mg} / \mathrm{L})$, respectively. The optimal washing time of the system is $1 \mathrm{~min}$.
\end{abstract}

\section{Introduction}

Biogas slurry is the inevitable outcome of the biogas project, and it is a kind of good organic fertilizer. Biogas slurry containing nitrogen, phosphorus, potassium and other elements which can increase the production and improve the quality of crops [1-5]. But the content of effective components in biogas slurry is low because of high water content. Generally, the concentration of the effective components is around $10 \%$ and the rest is free water [6]. In the off-season of fertilizer demand, the storage of biogas slurry needs a large amount of space. Due to lack of storage space, emissions of biogas slurry will cause environmental pollution and waste of nutrients. In order to avoid the occurrence of this phenomenon, concentrating the effective group in the biogas slurry to remove excess water can reduce storage space of the biogas slurry. Compared with other technology, membrane technology may be a good solution because it does not change the thermalization, chemical and biological characteristics of the substance, and the material does not occur phase transition [7]. The membrane concentration can improve the concentration of effective components in the biogas slurry, reduce the volume, and increase the utilization value. Song Chengfang et al [8, 9] studied the separation effect of biogas slurry using ultrafiltration and nanofiltration membrane. Concentration of total phosphorus increased to about 309 times. Concentration of other nutrients also obtains the varying degree increase, and biogas slurry can further be configured the foliar fertilizer or other exploitation and utilization. Han Jin used the nanofiltration membrane for separation of biogas slurry [10]. The concentrated liquid is used in the preparation of liquid fertilizer, and water quality of permeate was fully met the water quality standards for irrigation. In this study, we used reverse osmosis membrane for concentration of phosphorus in simulated biogas slurry. According to the content of total phosphorus in actual biogas slurry [11], in the experiment three different initial phosphorus concentrations (60 mg / L, $90 \mathrm{mg} / \mathrm{L}, 120 \mathrm{mg} / \mathrm{L}$ ) of simulated biogas slurry were selected. The concentrate effect of biogas slurry with reverse osmosis membrane under the condition of different initial phosphorus concentration was analyzed. 


\section{Materials and method}

\section{Materials}

The chemical reagents used in the experiment were all analytically pure. Simulated biogas slurry was prepared in the experiment. $1 \mathrm{~g} / \mathrm{L}(\mathrm{P})$ phosphorus stock liquid was prepared by potassium dihydrogen phosphate. The phosphorus solutions of different concentrations were obtained by the dilution of the stock liquid.

\section{Experimental equipment}

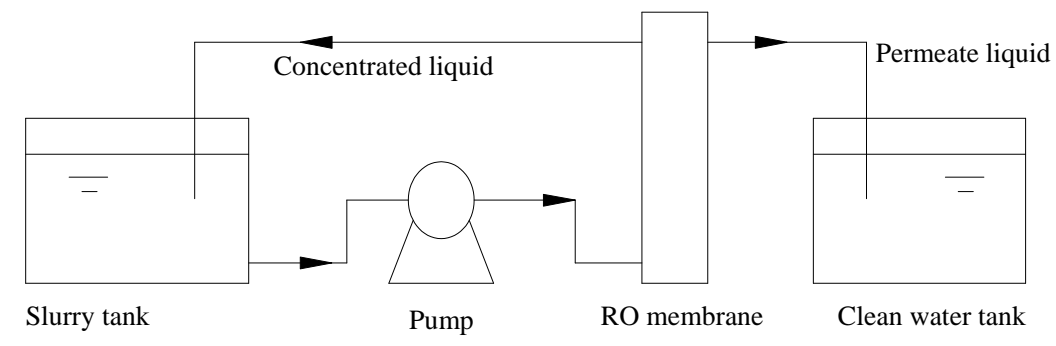

Fig. 1 Test device

Reverse osmosis membrane system for concentration of biogas slurry is shown in Fig.1. The system consists of pump and reverse osmosis membrane module. Simulated biogas slurry in slurry tank is pumped into the reverse osmosis membrane module firstly, and then the concentrated liquid through the reverse osmosis membrane returned to the concentrated pool to recycle concentration and permeate liquid went into clean water tank. The phosphorus concentration of concentrated liquid and permeate liquid under the condition of different concentrated time were determinated. The washing operation of reverse osmosis membrane was carried on after every experiment, and the changes of phosphorus concentration in flushing effluent with time were analyzed.

\section{Method}

The main analysis index of this experiment is total phosphorus. Total phosphorus was determined by ammonium moly date spectrophotometric method (GB11893-89).

\section{Results and discussion}

The change of water yield with time

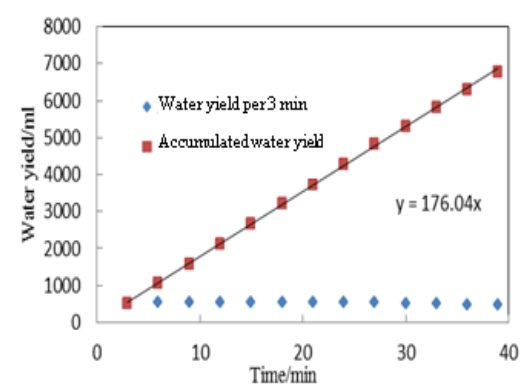

(a) $60 \mathrm{mg} / \mathrm{L}$

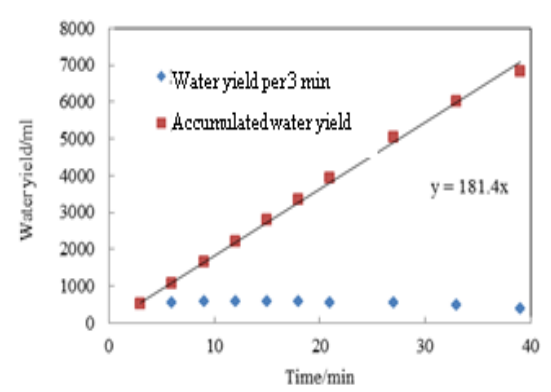

(b) $90 \mathrm{mg} / \mathrm{L}$

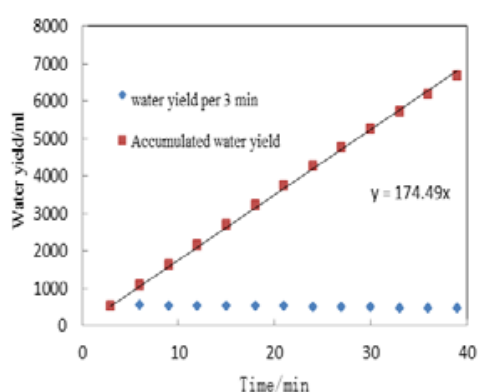

(c) $120 \mathrm{mg} / \mathrm{L}$

Fig.2 Variation of water production with time

Membrane flux is an important technological parameter of membrane separation process, and refers to the flow of the unit membrane area within the unit time. Membrane flux was determined by the external driving force and membrane resistance. The external driving force includes driving force, osmotic pressure, feed composition, feed composition etc. The influence factors of membrane resistance include membrane thickness, pore size and its distribution, physical and chemical properties of membrane materials etc. The variation of the amount of water production with time was shown in Fig.2. It can be seen from the Fig.2 that the water production in the same time (each 3 
min) did not change much under different initial phosphorus concentrations, and only have a little reduction in the final stage of concentration. This is because operating pressure increased continuously during concentrated process, so that the water output is kept at a relatively stable level. By linear fitting of cumulative water production and time, water production in the unit time of the reverse osmosis membrane can be obtained. From the slope of the fitting equation, the water production of unit time decreases gradually with the increase of the initial phosphorus concentration (from $181.4 \mathrm{ml} / \mathrm{min}$ to $174.49 \mathrm{ml} / \mathrm{min}$ ).In general, the membrane flux decreased with the increase of the enrichment time. This is because the influent concentration of reverse osmosis membrane was gradually increasing along with delay of enrichment. The increasing ion concentration can make the osmotic pressure of the concentrated water side of membrane increase and reduce the effective osmotic pressure [12].At the same time, the material deposited on the membrane surface increased with the growth of time, and the formation of resistance will also reduce water production of the membrane

\section{Concentrate and permeate changes with time}

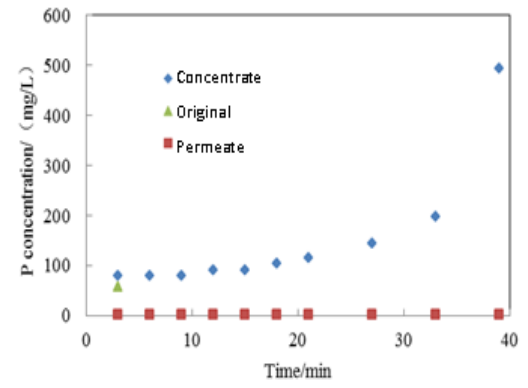

(a) $60 \mathrm{mg} / \mathrm{L}$

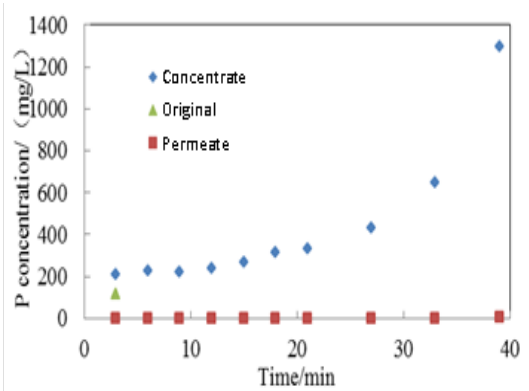

(b) $90 \mathrm{mg} / \mathrm{L}$

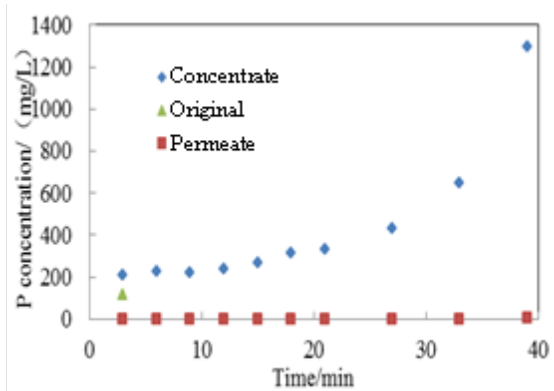

(c) $120 \mathrm{mg} / \mathrm{L}$

Fig.3 Concentrate and permeate changes with time

The changes of the phosphorus concentration in concentrate and permeate with time is shown in Figure 3. For the simulated biogas slurry of different initial phosphorus concentration, phosphorus content of permeate was very low, less than $3 \mathrm{mg} / \mathrm{L}$, which could meet Class II of pollutant discharge standard of urban sewage treatment plant. The phosphorus content in the concentrate increased rapidly after a slow increase. This is because the water content of the concentrated liquid reduced gradually along with the increase of permeates water. After biogas slurry with different initial phosphorus concentration (60 mg / L, $90 \mathrm{mg} / \mathrm{L}, 120 \mathrm{mg} / \mathrm{L}$ ) was concentrated, phosphorus concentration of concentrate effluent eventually increased by 7.8 times, 8 times, 10.4 times and phosphorus concentration of slurry tank were $470.4 \mathrm{mg} / \mathrm{L}, 678.2 \mathrm{mg} / \mathrm{L}$, and $842.3 \mathrm{mg} / \mathrm{L}$, respectively.

\section{The relationship between concentration multiple and time}

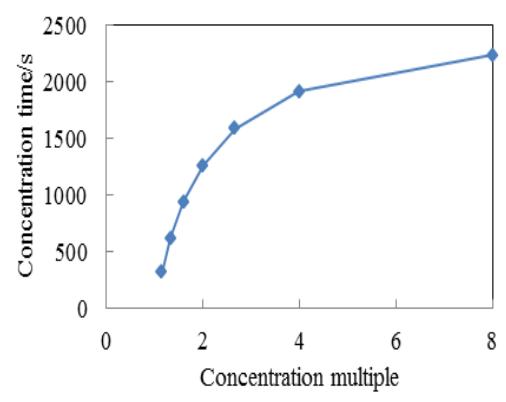

(a) $60 \mathrm{mg} / \mathrm{L}$

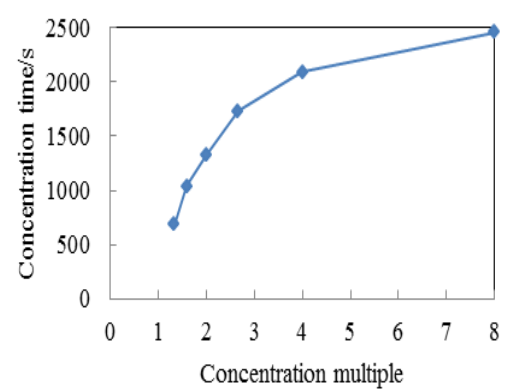

(b) $90 \mathrm{mg} / \mathrm{L}$

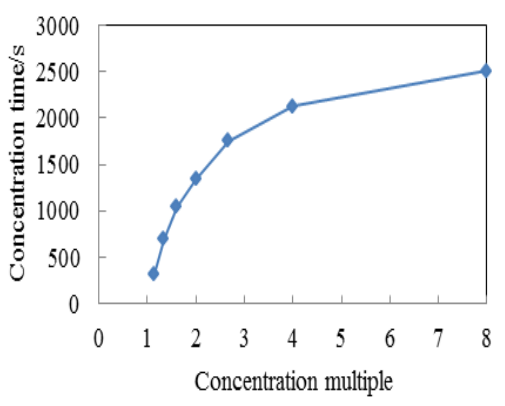

(c) $120 \mathrm{mg} / \mathrm{L}$

Fig.4 The relationship between concentration multiple and time

After going through the reverse osmosis system, the volume of biogas slurry will be reduced. The degree of volume reduction is measured by the concentration multiple. Volume reduction of concentrated liquid can reduce space for the biogas slurry storage and transportation costs, in terms of this aspects the bigger concentration multiple is better. But considering the membrane properties, system investment and operating costs, the concentration multiply is not infinite. At present, some 
advanced reverse osmosis system can achieve the control of the concentration multiply by setting the expected recovery rate [13]. Relationship between concentration multiple and permeate volume of biogas slurry can be shown in Fig 5 . From the figure, it can be seen that the volume of permeate liquid decreases gradually with the increase of the unit concentration multiply. This is because the volume of permeate liquid gradually increased with the increasing time, and the amount of permeate needed to increase the unit concentration multiply decreases.

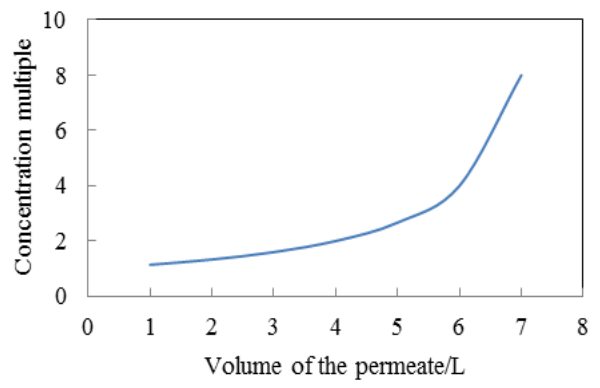

Fig.5 Relationship between concentration multiple and permeate volume

\section{Variation of washing water with time}

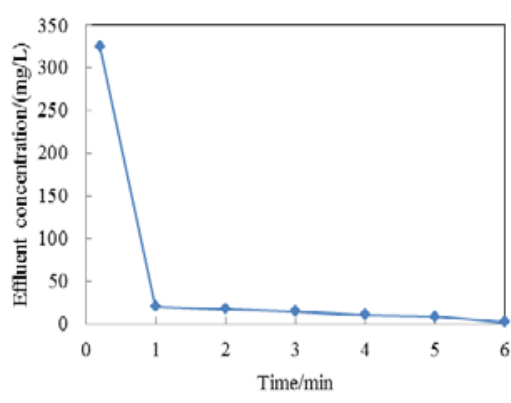

(a) $60 \mathrm{mg} / \mathrm{L}$

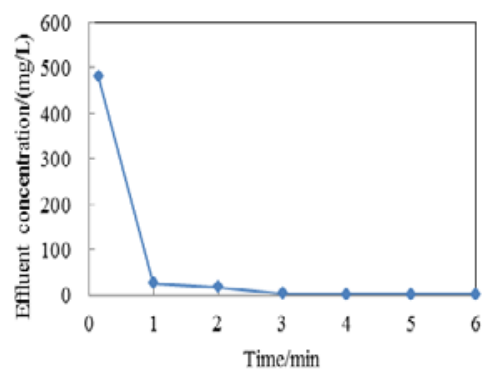

(b) $90 \mathrm{mg} / \mathrm{L}$

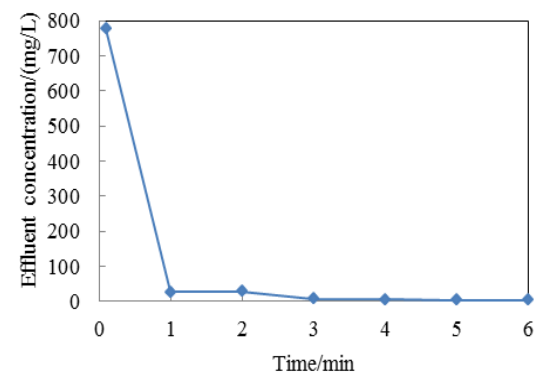

(c) $120 \mathrm{mg} / \mathrm{L}$

Fig. 6 Variation of washing water with time

The stability of membrane flux and the removal rate of solute are usually used as important indexes to evaluate pressure membrane system. In the process of biogas slurry concentration, due to the deposition of pollutants in the membrane surface and the channel, an increase of membrane resistance cause the decrease of the effective pressure difference and result in a decline in the flux of the membrane. In order to make the system run stably, the membrane module must be cleaned regularly. Reverse osmosis membrane is different from the ultrafiltration and microfiltration membrane, it cannot carry out the backwashing, and only can do the surface washing operation. In this experiment, washing operation of membrane was carried out after each operation of biogas slurry concentrating. Variation of washing water with time can be seen in Fig.6. It can be seen that the phosphorus concentration in the flushing effluent is higher in the initial stage, and it is kept in a very low level after a minute. So the best washing time was $1 \mathrm{~min}$.

\section{Conclusions}

The use of reverse osmosis membrane system for the concentration of biogas slurry can solve the existing problems in the process of storage and transportation. This study investigates the concentration effect of simulated biogas slurry with different initial phosphorus using reverse osmosis membrane. The results show that the water production of the system changes little with the increase of time, but the unit water production decreases gradually with the increase of the initial phosphorus concentration. The phosphorus content of the concentrate increases firstly slowly and then transforms to increase dramatically. Phosphorus concentration of concentrated liquid effluent with biogas slurry of different initial phosphorus concentration (60 mg / L, $90 \mathrm{mg} / \mathrm{L}, 120 \mathrm{mg} / \mathrm{L}$ ) eventually increased by 7.8 times, 8 times, 10.4 times, respectively. The increase amount of system running time required by increasing a unit concentration multiple continuously reduce. This is due to the gradual reduction of the amount of permeate water needed to increase the unit concentration 
multiply. The optimal flushing time of the system is $1 \mathrm{~min}$.

\section{Acknowledgements}

This research was supported by the Fundamental Research Funds for the Central Universities (FRF-MP-13-001B), International Scientific and Technological Cooperation and Exchange Projects (2013DFG92620) and Beijing Science and Technology Program (D141100001214003).

\section{References}

[1] X.L. Han, B.W. Li, W. Liu, et al. Effects of applying biogas slurry-based fertilizer on the yield, quality and nitrogen use efficiency of rape [J].Journal of Agricultural University of Hebei. 2012(03): 20-24.

[2] Q.Q. Zhou, Y.K. Wang, J. Li, et al. Effects of applying biogas liquid manure on the growth and quality of Lycium barbarum in Jingtai Electric-Irrigation Region [J]. Journal of South China Agricultural University. 2013(01): 12-17.

[3]W.P. Wang, X.M. Lu, Z.H. Wei, et al. Influence of applying biogas slurry on yield and quality of citrus and soil environment [J]. Journal of Agro-Environment Science. 2011(11): 2300-2305.

[4]W. Tang, J. Wu, B.Y. Sun, et al. Effects of application amounts of biogas slurry on yield and quality of rice [J].Journal of Agro—Environment Science. 2010(12): 2268-2273.

[5]W.P. Wang, F.X. Zhu, X.Y. Chen, et al. Effects of biogas slurry irrigation on soil quality and yield quality in Brassica chinensis [J].Acta agriculture Zhejiangensis. 2010(01): 73-76.

[6]T.H. Wang,Y.G. Li, J.J. Li, et al. Analysis and revelation of hungarian agricultural machinery market development during of the period of transfer society [J]. Agricultural Mechanization Research. 2013(03): 242-244.

[7]K.Q. Liang, Z. Yan, Q.Y. Wei, et al. Search on concentration of biogas slurry based on reverse osmosis [J]. China Biogas. 2012(2): 12-14.

[8]C.F. Song, S.D. Shan, M.X. Zhang, et al. Study on concentration of biogas slurry from livestock using membrane technology[J]. China water \& wastewater. 2011(3): 84-86.

[9]C.F. Song, S.D. Shan, M.X. Zhang, et al. Concentration and determination of composition of biogas slurry [J]. Transactions of the CSAE. 2011(12): 256-259.

[10]J. Han. Study on biogas slurry concentration and separation by membrane and liquid fertilizer preparation technology[D]. Zhejiang Forestry University, 2009.

[11]H.M. Jin, Z.Z. Chang, X.M. Ye, et al. Physical and chemical characteristics of anaerobically digested slurry from large-scale biogas project in Jiangsu Province [J]. Transactions of the CSAE. 2011(01): 291-296.

[12]G. R. Xu. The research on concentrations technology for biogas slurry using nanofiltration membrane and subsequent development of concentrated biogas slurry as liquid organic fertilizer [D]. Zhejiang University, 2012.

[13]K.Q. Liang, Z. Yan, M. Zhu, et al. Application research of reverse osmosis in concentrating biogas slurry from biogas projects [J]. Journal of China University of Mining \& Technology. 2011(3): 470-475. 